Supplementary Information for:

\title{
Large-Grained Cylindrical Block Copolymer Morphologies by One-Step Room- Temperature Casting
}

\author{
Arkadiusz A. Leniart, ${ }^{1}$ Przemyslaw Pula, ${ }^{1}$ Esther H. R. Tsai, ${ }^{2}$ Pawel W. Majewski ${ }^{1 *}$
}

*Email: pmajewski@chem.uw.edu.pl

\author{
${ }^{1}$ Department of Chemistry, University of Warsaw, Warsaw, 02089, Poland \\ ${ }^{2}$ Center for Functional Nanomaterials, Brookhaven National Laboratory, Upton, NY, 11973, \\ USA
}

\section{Film drying rates}

Table S1 shows the wet film drying rates calculated from the in situ thickness measurements during spin-coating of $0.8 \mathrm{wt} . \%$ solutions of S2VP C116 at $2000 \mathrm{rpm}$ at $23{ }^{\circ} \mathrm{C}$ in the absence of additional convection other than that caused by the spinning motion and gentle flow of inert gas purging the spincoater motor assembly. The rates for pure toluene and mesitylene solutions are approximate extrapolations based on a few recorded data points.

Table S1. Film drying rates of pure solvents and solvent mixtures at room temperature measured in situ during spin-coating at $2000 \mathrm{rpm}$ at $23{ }^{\circ} \mathrm{C}$. The initial concentration of $\mathrm{C} 116$ was $0.8 \mathrm{wt}$. \%. Data obtained by fitting spectral reflectance curves recorded at normal incidence in 300-800 $\mathrm{nm}$ range with Filmetrics F20 spectral reflectometer.

$\begin{array}{ccc}\text { Solvent } & \text { Ratio wt./wt. } & \text { Evaporation rate }\left[\mathbf{n m ~ s}^{-\mathbf{1}}\right] \\ \text { Tol } & -- & \sim 1000 \\ \text { Mes } & -- & \sim 200 \\ \text { DMOT/Tol } & 1: 9 & 4.1 \\ \text { TMOT/Tol } & 1: 9 & 1.4 \\ \text { DMOT/Tol } & 1: 4 & 3.5 \\ \text { TMOT/Tol } & 1: 4 & 0.6 \\ \text { DMOT/Tol } & 1: 1 & 3.8\end{array}$



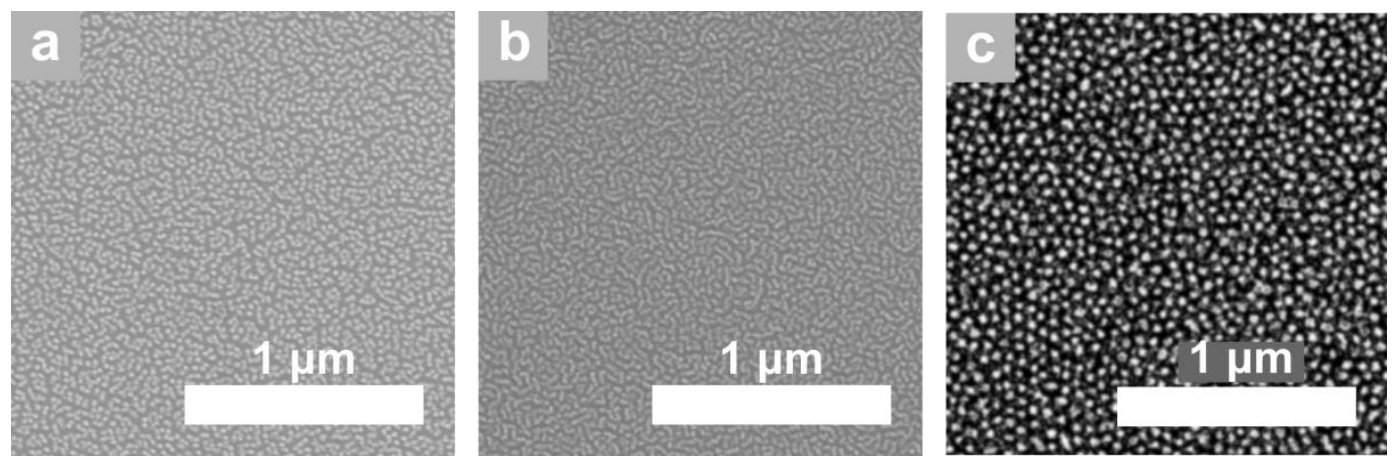

Figure S1. Comparison of S2VP C116 morphologies obtained by a) casting from $0.8 \%$ toluene solution at $2 \mathrm{krpm}$ without further annealing, b) $0.8 \%$ mesitylene solution at $2 \mathrm{krpm}$ without further annealing, c) casting from $1 \%$ toluene solution at $2 \mathrm{krpm}$ and thermally annealed for $16 \mathrm{~h}$ at $200{ }^{\circ} \mathrm{C}$ in vacuum. Poly(2-vinylpyridine) blocks were converted to $\mathrm{Al}_{2} \mathrm{O}_{3}$ replica before SEM imaging.

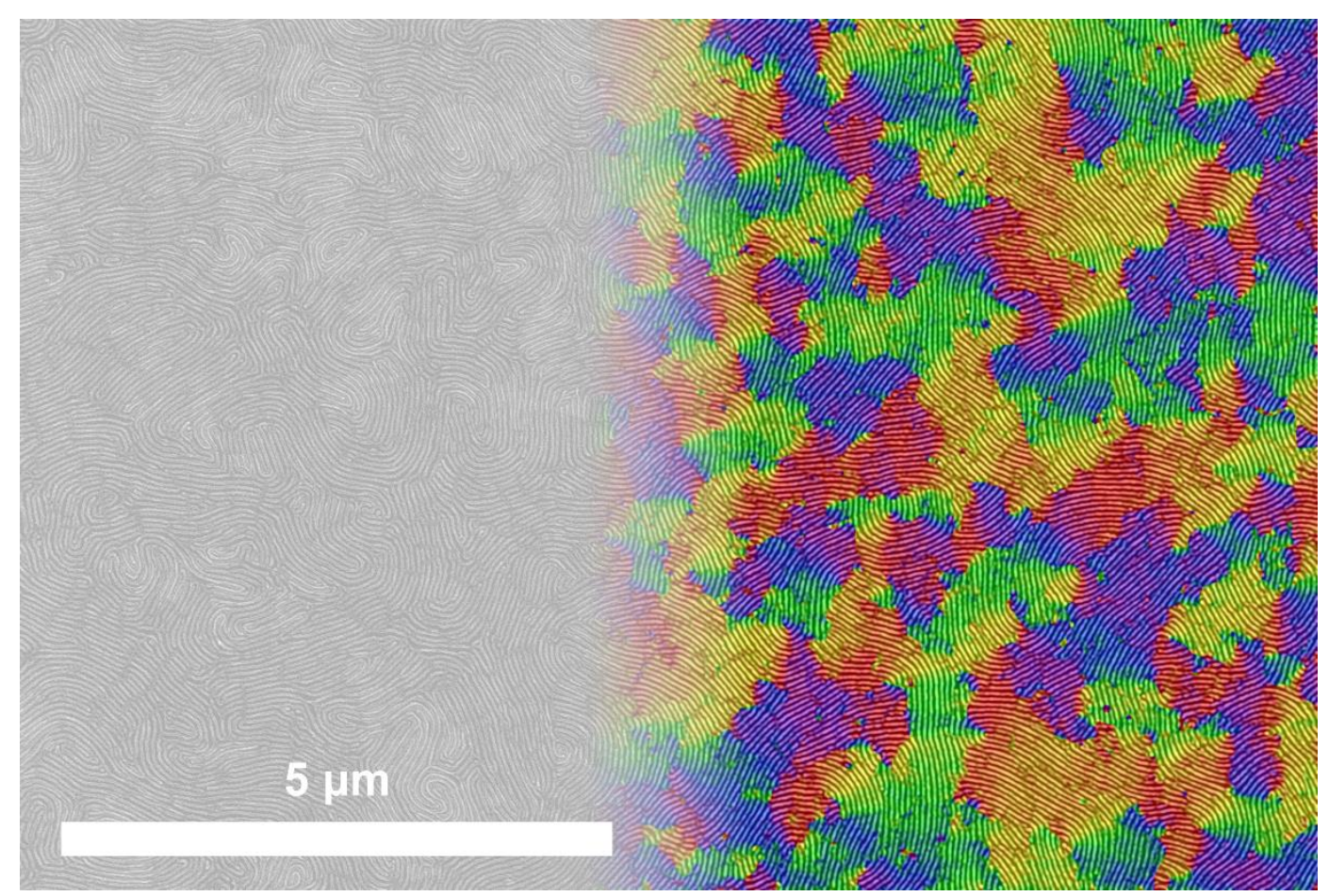

Figure S2. SEM image of the as-cast S2VP C116 morphology obtained by spin-casting from $0.8 \%$ TMOT/Tol 1:9 mixture at room temperature. Poly(2-vinylpyridine) blocks were converted to $\mathrm{Al}_{2} \mathrm{O}_{3}$ replica prior to SEM imaging. The average grain size at three distinct sample locations was $310 \pm 40$ $\mathrm{nm}$.

In the case of high TMOT concentration in the casting mixture, the resulting morphology is a combination of horizontal cylinders and reticular perforated lamellae (Figure S3). 


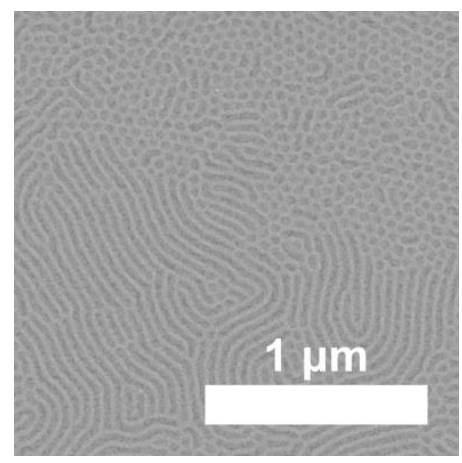

Figure S3. SEM image of the as-cast S2VP C116 morphology obtained by spin-casting from $0.8 \%$ TMOT/Tol 1:4 mixture at room temperature. Poly(2-vinylpyridine) blocks were converted to $\mathrm{Al}_{2} \mathrm{O}_{3}$ replica prior to SEM imaging.

The drying rate of the DMOT/Tol 1:4 mixture is strongly affected by the substrate's temperature as depicted in Figure S3. For the lowest tested temperature $\left(15^{\circ} \mathrm{C}\right)$, the drying rate can be as low as 0.2 $\mathrm{nm} / \mathrm{s}$. We observed, however, that under these conditions the film is drying non-uniformly, with a visible motion of the evaporation front, and the exact drying rate and thus the processing history is likely position-dependent.

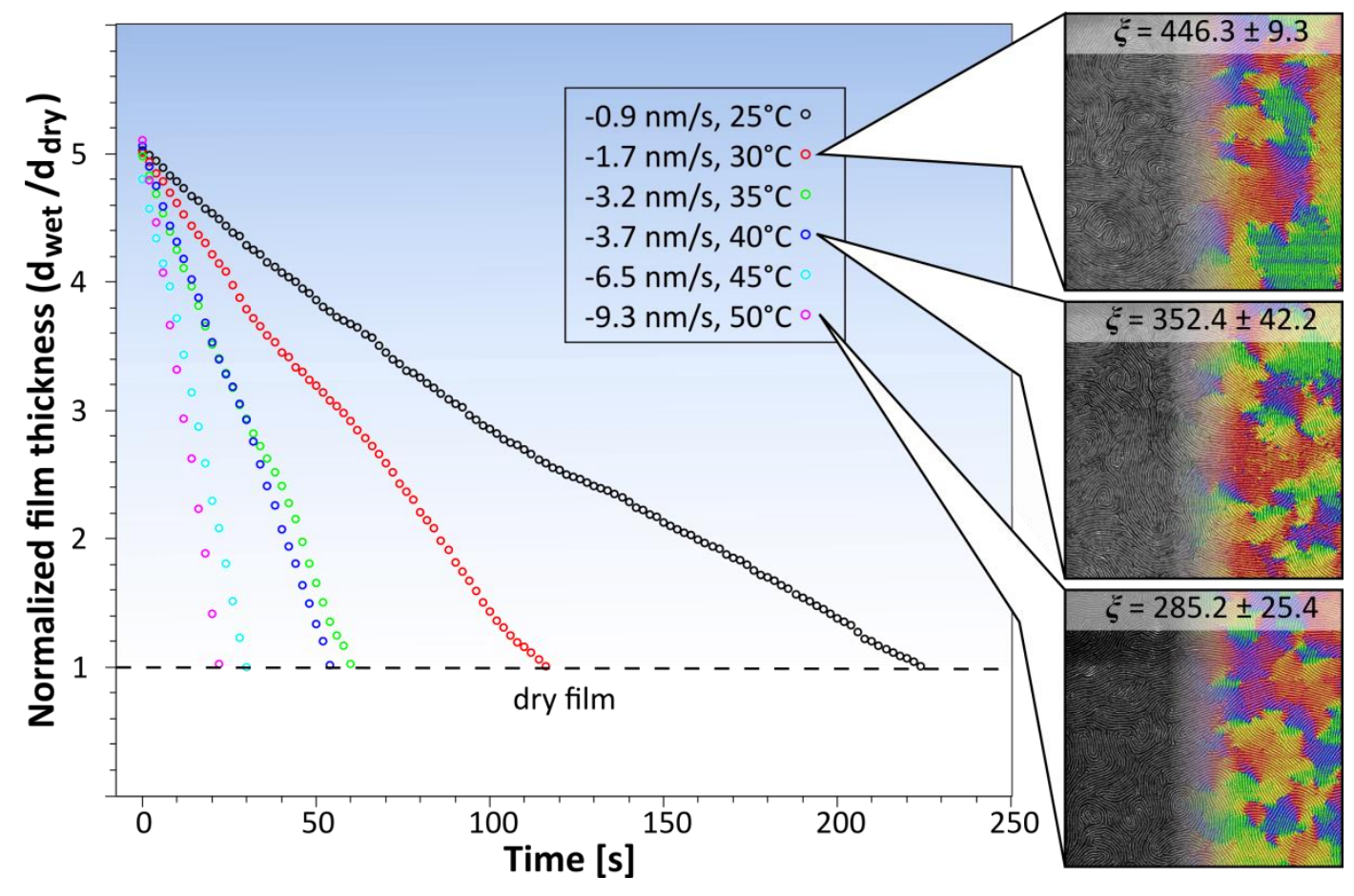

Figure S4. Film-thickness vs. time for S2VP C116 wet films cast from 0.8\% DMOT/Tol 1:4 mixture evaporating on a thermostated hot-plate. The inset shows the calculated evaporation rates approximated by linear fits for $d=50-250 \mathrm{~nm}$ (dry film thickness $\approx 50 \mathrm{~nm}$ ). The insets show SEM images of the resulting morphologies and calculated grain-size values.

"Evaporation caps" shown in Figure S4 reduce the evaporation rate, offer spatially-uniform evaporation, and allow high-temperature long-time evaporation experiments. The opening in the cylindrical evaporation cap acts a dual role of the solvent evaporation route and the thickness monitoring window. The diameters of the orifice in each cap $(5 \mathrm{~mm}, 7 \mathrm{~mm}, 10 \mathrm{~mm})$ are incremented to step-up the aperture 
areas in the 1:2:4 sequence. The corresponding evaporation rates ratio was observed only at the highest temperature tested $\left(45^{\circ} \mathrm{C}\right)$. The drying rate can be accelerated by introducing a flow of inert gas $\left(\mathrm{N}_{2}\right)$ over the sample surface. Special care was taken to homogenize the flow of nitrogen directed onto the film by a sintered-metal gas diffuser $(\varphi=25 \mathrm{~mm})$ directed from a $\sim 60 \mathrm{~mm}$ distance at a $\sim 60^{\circ}$ angle at the drying sample. The gas flow-rates were adjusted by a needle valve and recorded by a variable-area flow meter (Dwyer). The evaporation rates are listed in Table S2.

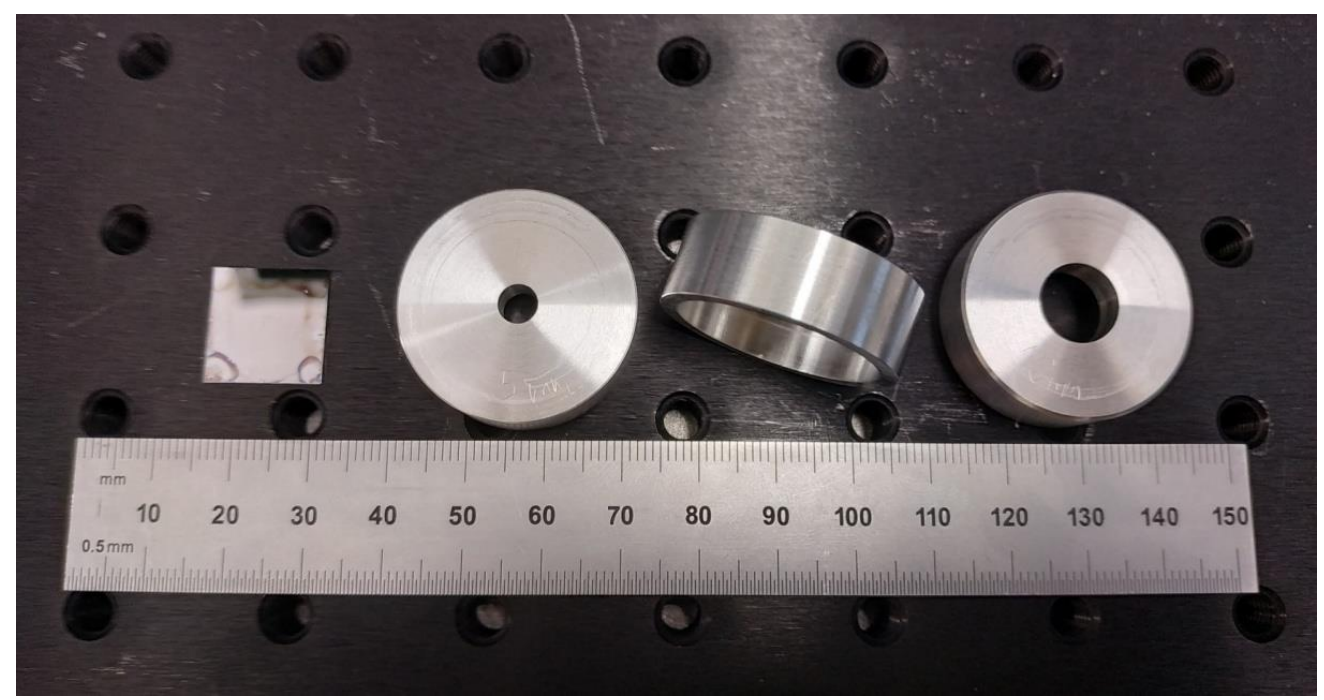

Figure S5. A photograph displaying a set of "evaporation caps" - low-profile hollow cylinders with circular openings used to slow down the evaporation of solvents while permitting the in situ thickness monitoring. The orifice diameter in each cap $(5 \mathrm{~mm}, 7 \mathrm{~mm}, 10 \mathrm{~mm})$ is incremented to step up the aperture area in the 1:2:4 sequence.

Table S2. Evaporation rate values measured in 500-50 nm thickness range for wet S2VP C116 films cast from a 0.8\% DMOT/Tol 1:4 mixture under various drying conditions.

\begin{tabular}{|c|c|c|c|c|}
\hline Temperature $\left[{ }^{\circ} \mathrm{C}\right]$ & 25 & 30 & 35 & 45 \\
\hline Orifice $\varphi=5 \mathrm{~mm}$ & 0.09 & 0.09 & 0.26 & 0.40 \\
\hline Orifice $\varphi=7 \mathrm{~mm}$ & 0.10 & 0.19 & 0.34 & 0.70 \\
\hline Orifice $\varphi=10 \mathrm{~mm}$ & 0.18 & 0.32 & 0.47 & 1.45 \\
\hline Free evaporation & 0.62 & 1.16 & 2.29 & 4.90 \\
\hline Flow $2 \mathrm{dm}^{3} \mathrm{~min}^{-1}$ & 1.52 & 2.09 & 3.81 & 8.44 \\
\hline Flow $4 \mathrm{dm}^{3} \min ^{-1}$ & 3.20 & 3.14 & 5.70 & 14.38 \\
\hline Flow $8 \mathrm{dm}^{3} \mathrm{~min}^{-1}$ & 5.65 & 6.63 & 12.68 & 21.32 \\
\hline
\end{tabular}




\section{Large-grained morphologies}

a

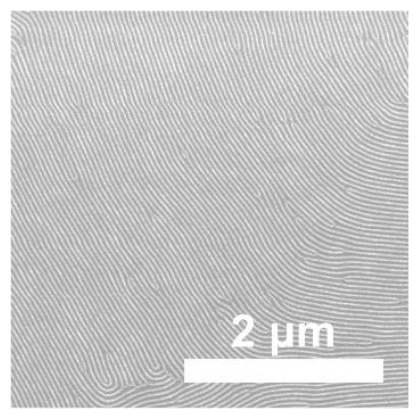

b

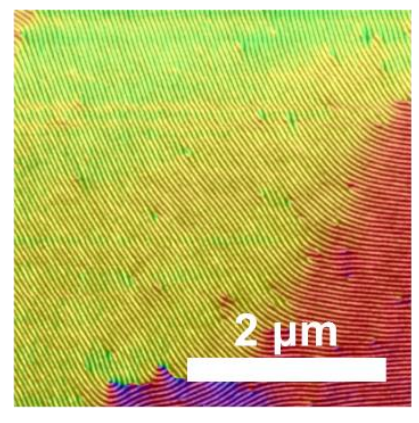

C

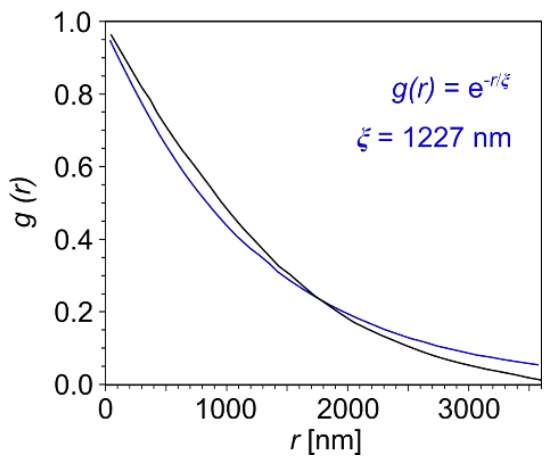

Figure S6. SEM image of large-domain S2VP C116 cast from a 0.8\% DMOT/Tol 1:4 mixture evaporating at $25^{\circ} \mathrm{C}$ under a cap with a $5 \mathrm{~mm}$ orifice. a) Native-color SEM image. b) False-color map of the azimuthal orientation of cylindrical BCP domains' in the same region. c) The domains' orientation autocorrelation function (black curve) was fitted with an exponential decay function (blue curve) to obtain the correlation, $\xi=1227 \mathrm{~nm}$. Poly(2-vinylpyridine) blocks were converted to $\mathrm{Al}_{2} \mathrm{O}_{3}$ replica before SEM imaging. $\xi$ values were calculated over a much larger area images $\left(\approx 100 \mu \mathrm{m}^{2}\right)$. 


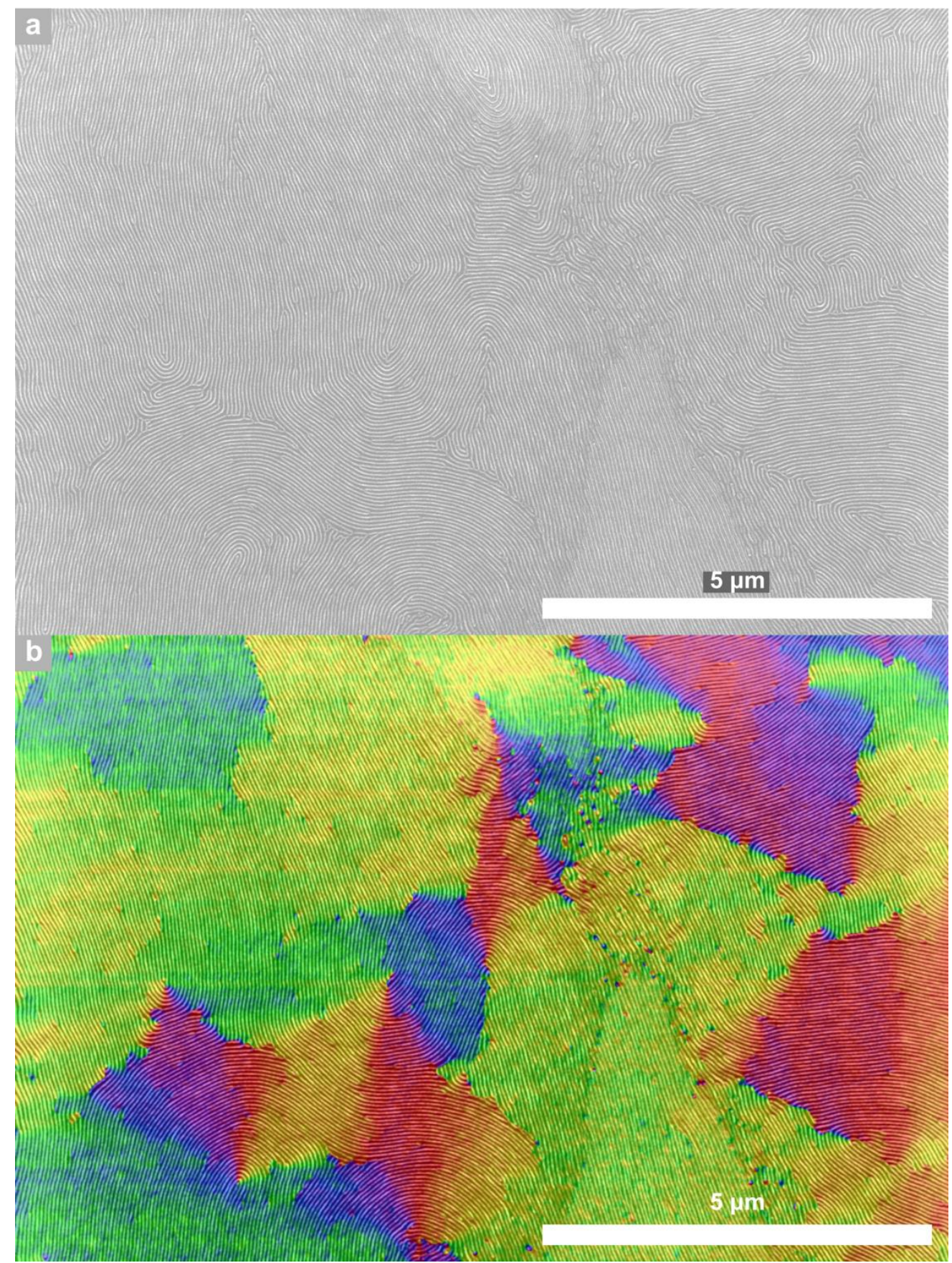

Figure S7. SEM image of a large-domain S2VP C116 cast from 0.8\% DMOT/Tol 1:4 mixture evaporating at $25{ }^{\circ} \mathrm{C}$ through a $5 \mathrm{~mm}$ orifice; $\xi=814 \mathrm{~nm}$. a) Native-color SEM image. b) False-color map of domains' azimuthal orientation of the same region. Poly(2-vinylpyridine) blocks were converted to $\mathrm{Al}_{2} \mathrm{O}_{3}$ replica prior to SEM imaging. 

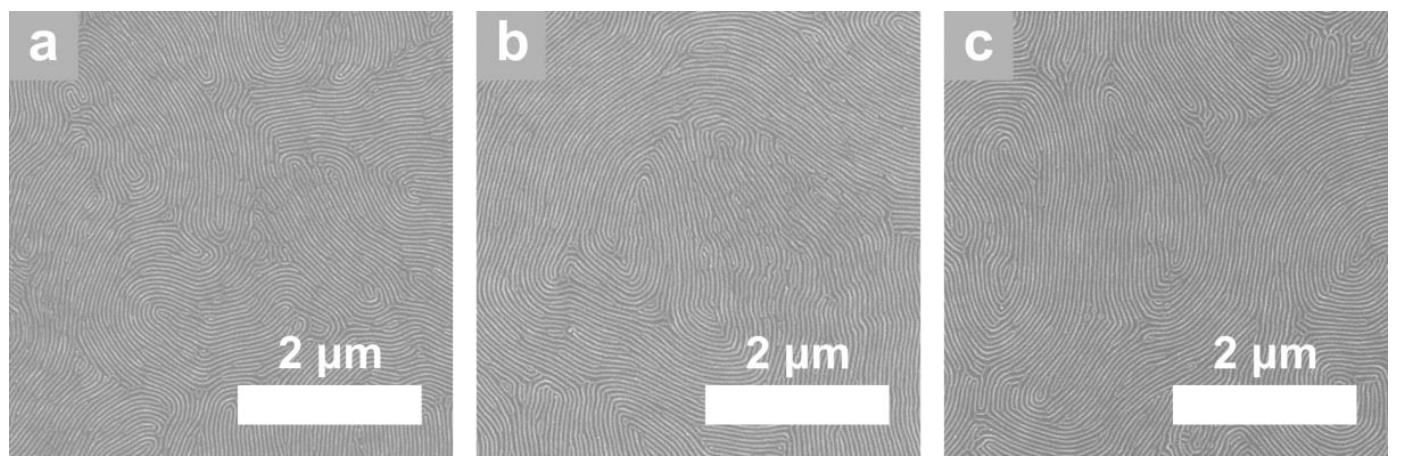

Figure S8. Comparison of S2VP C116 morphologies obtained by SEA by solvent evaporation through the cap with $10 \mathrm{~mm}$ orifice at $25{ }^{\circ} \mathrm{C}(\mathrm{a}), 35^{\circ} \mathrm{C}$ (b), and $45^{\circ} \mathrm{C}$ (c) cast from the $0.8 \%$ DMOT/Tol 1:4 mixture to an initial $500 \mathrm{~nm}$ thickness. The average $\xi$ values were $1262 \mathrm{~nm}$ (a), $817 \mathrm{~nm}$ (b), and $586 \mathrm{~nm}$ (c) obtained after $280 \mathrm{~s}, 105 \mathrm{~s}$, and $35 \mathrm{~s}$, respectively. Poly(2-vinylpyridine) blocks were converted to $\mathrm{Al}_{2} \mathrm{O}_{3}$ replica prior to SEM imaging. 


\section{Compatibility with the blade- and dip-coating techniques}

\section{Blade-coating}

The custom-built blade-coating apparatus following the design by Stafford $e t$ al. ${ }^{1}$ was used to deposit thin polymer films on Si substrates. A $25 \mathrm{~mm}$-wide stationary microscope glass slide oriented at an $8^{\circ}$ angle positioned $200 \mu \mathrm{m}$ above a substrate was used to spread the BCP solution. The motion of the substrate relative to the blade was realized by the motorized linear stage (Newport, ILS200CC). Before the coating, $16 \mu \mathrm{l}$ of $0.8 \% \mathrm{C} 116$ in DMOT/Tol 1:4 mixture was deposited in the gap between the blade and substrate and spread over the $70 \mathrm{~mm}$ distance by the computer-controlled motorized stage at constant acceleration $\left(18 \mathrm{~mm} \mathrm{~s}^{-2}\right)$ producing a film with a thickness gradient.
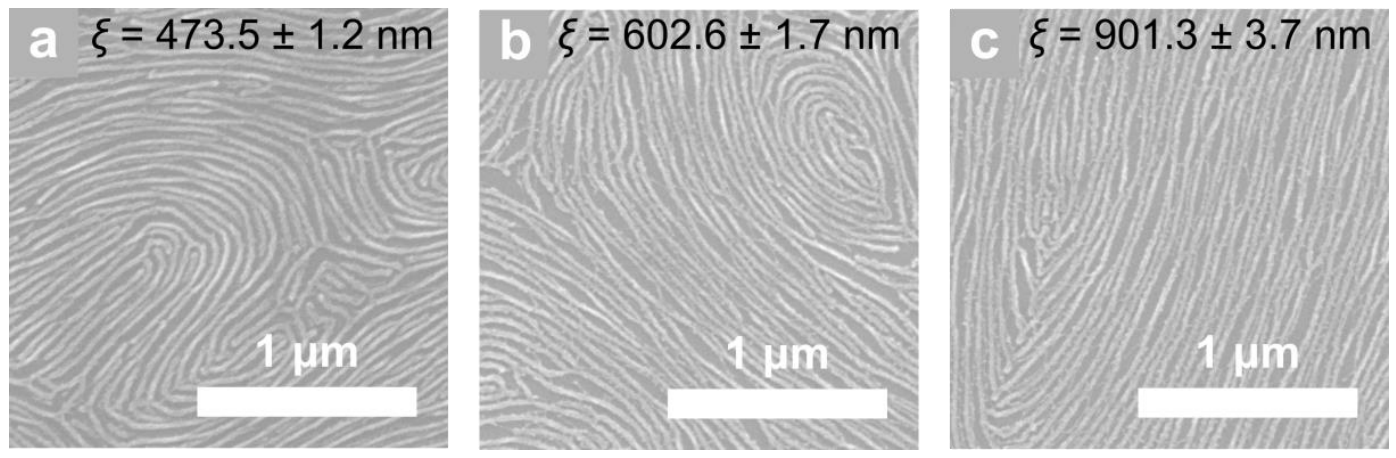

Figure S9. Comparison of S2VP C116 morphologies obtained by blade-coating of 0.8\% BCP solution in DMOT/Tol 1:4 mixture at the increasing blade velocity: a) $13.4 \mathrm{~mm} \mathrm{~s}^{-1}(t \approx 40 \mathrm{~nm})$, b) $30 \mathrm{~mm} \mathrm{~s}^{-1}(t$ $\approx 65 \mathrm{~nm}), \mathrm{c})$ and $44.5 \mathrm{~mm} \mathrm{~s}^{-1}(t \approx 75 \mathrm{~nm})$ with the respective correlation length values measured for images of a much larger area $\left(\approx 100 \mu \mathrm{m}^{2}\right)$. Poly (2-vinylpyridine) blocks were converted to $\mathrm{Al}_{2} \mathrm{O}_{3}$ replica prior to SEM imaging.

\section{Transfer of Ordered Films}

We demonstrate a possibility of the single-step cast S2VP C116 film transfer onto a curved substrate i.e. pencil graphite utilizing a transfer method described in detail elsewhere. ${ }^{2}$ In short, a thin layer of $10 \%$ of poly(4-styrene sodium sulfonate) was spin-cast at $3 \mathrm{krpm}$ on a silicon substrate and then baked at $120{ }^{\circ} \mathrm{C}$ in air for $1 \mathrm{~min}$. Then, the spin-casting of $0.8 \%$ DMOT/Tol 1:4 mixture at $2 \mathrm{krpm}$ was performed and the film was further vacuum baked at $150{ }^{\circ} \mathrm{C}$ for $10 \mathrm{~min}$ to remove residual solvent. The C116 film was floated onto the water surface by gradual immersion of the substrate using a dip-coater motorized arm (L2006A1, Ossila Ltd.) - the layer exhibited no visible mechanical damage. A pencil graphite surface was activated in the plasma etcher (120 mTorr $\mathrm{O}_{2}, 120 \mathrm{~W}$ RF power, $35 \mathrm{kHz}, \mathrm{PE}-25$, Plasma Etch) for 10 seconds before the deposition process. The film was gently picked up on the graphite and dried in air. 

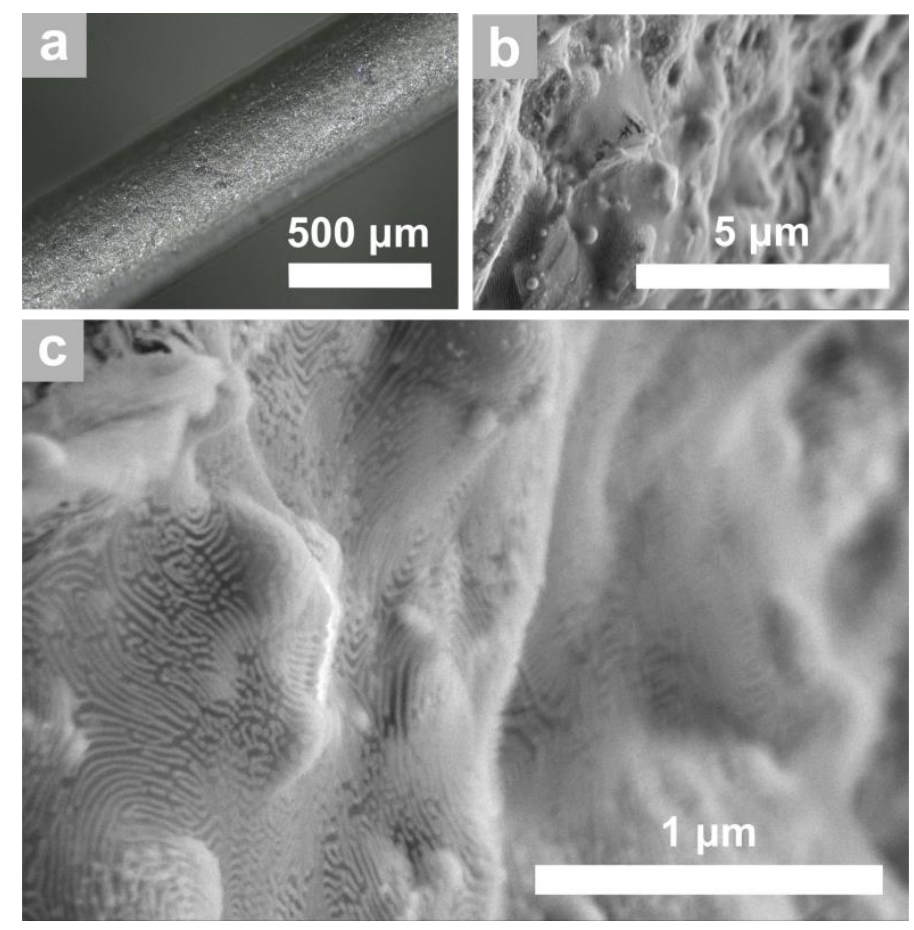

Figure S10. a) Low-magnification optical microscopy image of a $0.5 \mathrm{~mm}$ pencil graphite coated with $\mathrm{C} 116$ thin film. b) and c) SEM images of the pencil graphite grafted with the S2VP C116 $\mathrm{Al}_{2} \mathrm{O}_{3}$ replica obtained by the wet-transfer method of the film initially deposited by spin-casting $0.8 \%$ S2VP C116 DMOT/Tol 1:4 mixture on a sacrificial layer coated Si substrate. Poly(2-vinylpyridine) blocks were converted to $\mathrm{Al}_{2} \mathrm{O}_{3}$ replica prior to SEM imaging.

\section{Dip-coating}

Dip-coating compatibility tests were carried out using a commercial dip-coater (Ossila L2006A1). Plasma-cleaned rectangular silicon substrates $(5 \mathrm{~mm} \times 50 \mathrm{~mm})$ were immersed in a $0.8 \% \mathrm{DMOT} / \mathrm{Tol}$ 1:4 mixture for 30 seconds. Several withdrawal speeds in the capillary or drainage regime (from 0.01 $\mathrm{mm} \mathrm{s}^{-1}$ to $5 \mathrm{~mm} \mathrm{~s}^{-1}$ ) were tested to find the optimal dip-coating conditions.
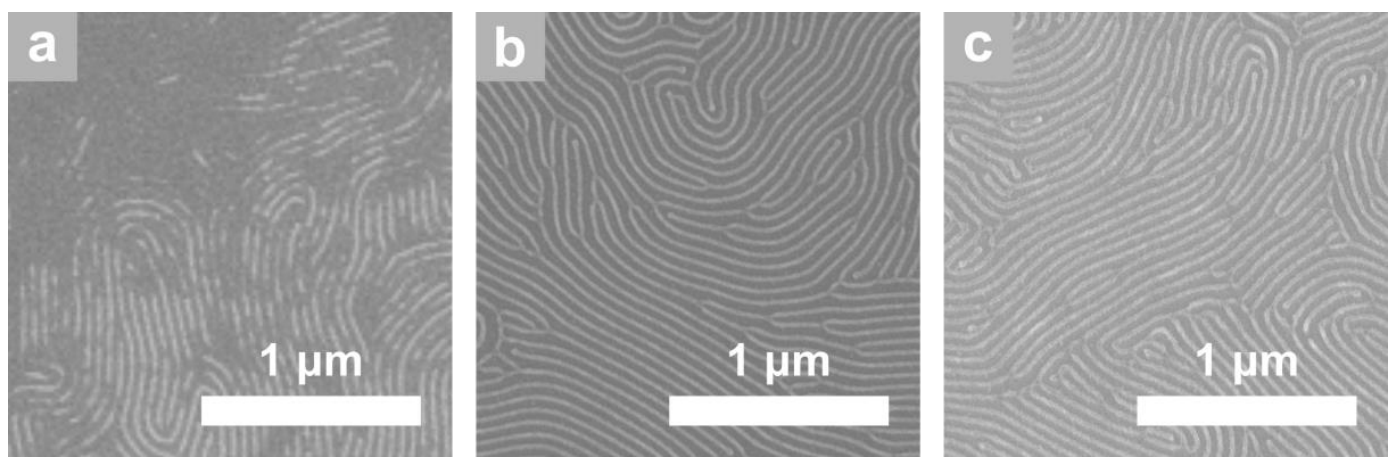

Figure S11. Comparison of S2VP C116 morphologies obtained by withdrawing a silicon substrate from the $0.8 \%$ S2VP C116 solution in DMOT/Tol 1:4 mixture at a) $0.1 \mathrm{~mm} \mathrm{~s}^{-1}$, b) $1 \mathrm{~mm} \mathrm{~s}^{-1}$, and c) $5 \mathrm{~mm} \mathrm{~s}^{-1}$. Poly(2-vinylpyridine) blocks were converted to $\mathrm{Al}_{2} \mathrm{O}_{3}$ replica prior to SEM imaging. 


\section{4. ${ }^{1} \mathrm{H}$ NMR analysis and Hansen solubility parameters calculation}

Table S3. Physical parameters and calculated Hansen solubility parameters for solvents used in the study.

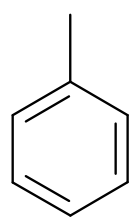<smiles>Cc1cc(C)cc(C)c1</smiles><smiles>COc1ccc(C)cc1OC</smiles><smiles>COc1cc(C)cc(OC)c1OC</smiles>

\begin{tabular}{|c|c|c|c|c|}
\hline & Toluene & $\begin{array}{c}1,3,5- \\
\text { trimethylbenzene }\end{array}$ & $\begin{array}{c}3,4- \\
\text { dimethoxytoluene }\end{array}$ & $\begin{array}{c}3,4,5- \\
\text { trimethoxytoluene }\end{array}$ \\
\hline Density $\left[\mathrm{g} \mathrm{cm}^{-3}\right]$ & 0.87 & 0.86 & 1.05 & 1.08 \\
\hline $\begin{array}{l}\text { Boiling point (at } 760 \\
\text { mmHg) }\left[{ }^{\circ} \mathrm{C}\right]\end{array}$ & 111 & 165 & $220^{3}$ & $273^{4}$ \\
\hline $\begin{array}{l}\text { Vapor pressure (at } \\
298 \mathrm{~K})[\mathrm{mmHg}]\end{array}$ & $26^{5}$ & $2.49^{6}$ & $0.17^{3}$ & $0.01^{4}$ \\
\hline $\begin{array}{l}\text { Hansen dispersion } \\
\text { term }\left(\delta_{\mathrm{d}}\right)\left[\mathrm{MPa}^{1 / 2}\right]\end{array}$ & $18.0^{7}$ & 14.7 & 16.0 & 15.6 \\
\hline $\begin{array}{l}\text { Hansen polar term } \\
\left(\delta_{\mathrm{p}}\right)\left[\mathrm{MPa}^{1 / 2}\right]\end{array}$ & $1.4^{7}$ & 0.8 & 6.1 & 7.6 \\
\hline $\begin{array}{l}\text { Hansen hydrogen- } \\
\text { bonding term }\left(\delta_{\mathrm{hb}}\right) \\
{\left[\mathrm{MPa}^{1 / 2}\right]}\end{array}$ & $2.0^{7}$ & 4.3 & 7.4 & 8.6 \\
\hline $\begin{array}{l}\text { Hansen solubility } \\
\text { parameter }\left(\delta_{\mathrm{t}}\right) \\
{\left[\mathrm{MPa}^{1 / 2}\right]}\end{array}$ & $18.3^{8}$ & 15.4 & 18.7 & 19.4 \\
\hline
\end{tabular}

Vapor pressure of 3,4,5-trimethoxytoluene (TMOT) is lower than 3,4-dimethoxytoluene (DMOT) and its relative concentration in the mixture with toluene is expected to increase faster than that of DMOT upon evaporation (when comparing mixtures at the same evaporation progress i.e., mass loss).

To track the composition evolution of the solvent mixture (in the liquid phase) during evaporation, a controlled evaporation experiment was performed. The progress of evaporation was monitored by placing a known amount $\approx 2 \mathrm{~g}$ ) of the solvent mixture (1:4 DMOT/Tol or TMOT/Tol) on an aluminum weighing pan inside a digital laboratory balance. The protective sash of the balance was opened to facilitate the evaporation. When $10 \%, 30 \%, 50 \%$, and $70 \%$ loss of the initial mass was reached, a small aliquot of the mixture was gently aspirated from the pan with a pipette and transferred into an NMR test tube filled with $\mathrm{CDCl}_{3}$. The mixture composition was analyzed with an NMR spectrometer (Agilent 400 $\mathrm{MHz}$ ). Quantification of the area under the peaks originating from methyl and methoxy group protons was performed with MestReNova NMR analysis software to determine the molar concentration ratio of DMOT/Tol and TMOT/Tol in each sample. The peak designated as A, located at $2.36 \mathrm{ppm}$, originates from the overlapping peaks of the methyl groups $(\mathrm{S}, 3 \mathrm{H})$ from toluene and DMOT or TMOT. The peak $\mathrm{B}$, at $3.85 \mathrm{ppm}$, originates from the methoxy group present only in DMOT or TMOT (, $6 \mathrm{H}$ and $\mathrm{S}, 9 \mathrm{H}$ for DMOT and TMOT, respectively). After accounting for the number of methoxy groups in DMOT and TMOT, the area under peak B was used, to estimate the relative inputs of toluene and DMOT or TMOT into the methyl peak area (peak A), enabling the calculation of their molar ratio. 
Hansen solubility parameters were calculated according to the Panayiotou group-contribution method. ${ }^{9}$ Tables S4-S6 list contributions to dispersive, polar, and hydrogen-bond fractions for 3,4dimethoxytoluene, 3,4,5-trimethoxytoluene, and 1,3,5-trimethylbenzene, respectively.

Table S4. The first- and second-order group approximation for the prediction of the dispersion $\left(\delta_{\mathrm{d}}\right)$ polar $\left(\delta_{\mathrm{p}}\right)$ and hydrogen bonding $\left(\delta_{\mathrm{hb}}\right)$ partial solubility parameters of 3,4-dimethoxytoluene (DMOT).

\begin{tabular}{|c|c|c|c|c|c|c|c|}
\hline 1st order & $\begin{array}{c}\text { Occurrences } \\
N\end{array}$ & $\begin{array}{c}\text { Contributions } \\
C\left(\delta_{\mathrm{d}}\right)\end{array}$ & $N C\left(\delta_{\mathrm{d}}\right)$ & $\begin{array}{c}\text { Contributions } \\
C\left(\delta_{\mathrm{p}}\right)\end{array}$ & $N C\left(\delta_{\mathrm{p}}\right)$ & $\begin{array}{c}\text { Contributions } \\
C\left(\delta_{\mathrm{hb}}\right)\end{array}$ & $N C\left(\delta_{\mathrm{hb}}\right)$ \\
\hline $\mathrm{ACH}$ & 3 & 0.1105 & 0.3315 & -0.5303 & -1.5909 & -0.4305 & -1.2915 \\
\hline$-\mathrm{CH}_{3}$ & 1 & -0.9714 & -0.9714 & -1.6448 & -1.6448 & -0.7813 & -0.7813 \\
\hline$-\mathrm{OCH}_{3}$ & 2 & -0.5828 & -1.1656 & 0.1764 & 0.3528 & 0.1460 & 0.2920 \\
\hline \multicolumn{8}{|l|}{ 2nd order } \\
\hline AC-O-C & 2 & 0.2568 & 0.5136 & 0.8153 & 1.6306 & 0.6092 & 1.2184 \\
\hline Constant, C & & & 17.3231 & & 7.3548 & & 7.9793 \\
\hline sum & & & 16.0312 & & 6.1025 & & 7.4169 \\
\hline
\end{tabular}

Table S5. The first- and second-order group approximation for the prediction of the dispersion $\left(\delta_{\mathrm{d}}\right)$ polar $\left(\delta_{\mathrm{p}}\right)$ and hydrogen bonding $\left(\delta_{\mathrm{hb}}\right)$ partial solubility parameters of 3,4,5-trimethoxytoluene (TMOT).

\begin{tabular}{|c|c|c|c|c|c|c|c|}
\hline 1st order & $\begin{array}{c}\text { Occurrences } \\
N\end{array}$ & $\begin{array}{c}\text { Contributions } \\
C\left(\delta_{\mathrm{d}}\right)\end{array}$ & $N C\left(\delta_{\mathrm{d}}\right)$ & $\begin{array}{c}\text { Contributions } \\
C\left(\delta_{\mathrm{p}}\right)\end{array}$ & $N C\left(\delta_{\mathrm{p}}\right)$ & $\begin{array}{c}\text { Contributions } \\
C\left(\delta_{\mathrm{hb}}\right)\end{array}$ & $N C\left(\delta_{\mathrm{hb}}\right)$ \\
\hline $\mathrm{ACH}$ & 2 & 0.1105 & 0.2210 & -0.5303 & -2.6515 & -0.4305 & -1.2915 \\
\hline$-\mathrm{CH}_{3}$ & 1 & -0.9714 & -0.9714 & -1.6448 & -1.6448 & -0.7813 & -0.7813 \\
\hline$-\mathrm{OCH}_{3}$ & 3 & -0.5828 & -1.7484 & 0.1764 & 0.5292 & 0.1460 & 0.4380 \\
\hline \multicolumn{8}{|l|}{ 2nd order } \\
\hline AC-O-C & 3 & 0.2568 & 0.7704 & 0.8153 & 2.4459 & 0.6092 & 1.8276 \\
\hline Constant. C & & & 17.3231 & & 7.3548 & & 7.9793 \\
\hline sum & & & 15.5947 & & 7.6245 & & 8.6026 \\
\hline
\end{tabular}

Table S6. The first- and second-order group approximation for the prediction of the dispersion $\left(\delta_{\mathrm{d}}\right)$ polar $\left(\delta_{\mathrm{p}}\right)$ and hydrogen bonding $\left(\delta_{\mathrm{hb}}\right)$ partial solubility parameters of 1,3,5-trimethylbenzene (mesitylene).

\begin{tabular}{lccccccc}
\hline \multicolumn{1}{c}{ 1st order } & $\begin{array}{c}\text { Occurrences } \\
\boldsymbol{N}\end{array}$ & $\begin{array}{c}\text { Contributions } \\
\boldsymbol{C}\left(\boldsymbol{\delta}_{\mathbf{d}}\right)\end{array}$ & $\boldsymbol{N C}\left(\boldsymbol{\delta}_{\mathbf{d}}\right)$ & $\begin{array}{c}\text { Contributions } \\
\boldsymbol{C}\left(\boldsymbol{\delta}_{\mathbf{p}}\right)\end{array}$ & $\boldsymbol{N C}\left(\boldsymbol{\delta}_{\mathbf{p}}\right)$ & $\begin{array}{c}\text { Contributions } \\
\boldsymbol{C}\left(\boldsymbol{\delta}_{\mathrm{hb}}\right)\end{array}$ & $\boldsymbol{N C}\left(\boldsymbol{\delta}_{\mathrm{hb}}\right)$ \\
\hline $\mathrm{ACH}$ & 3 & 0.1105 & 0.3315 & -0.5303 & -1.5909 & -0.4305 & -1.2915 \\
$-\mathrm{CH}_{3}$ & 3 & -0.9714 & -2.9142 & -1.6448 & -4.9344 & -0.7813 & -2.3439 \\
Constant. C & & & 17.3231 & & 7.3548 & & 7.9793 \\
sum & & & $\mathbf{1 4 . 7 4 0 4}$ & & $\mathbf{0 . 8 2 9 5}$ & & $\mathbf{4 . 3 4 3 9}$
\end{tabular}


$\chi$ interaction parameter can be calculated from Hildebrand parameters in accord with the HildebrandScatchard regular solution theory:

$$
\chi=\chi_{\mathrm{H}}+\chi_{\mathrm{S}}=\frac{V}{R T}\left(\delta_{\mathrm{i}}-\delta_{\mathrm{j}}\right)^{2}+0.34
$$

where $\chi_{\mathrm{H}}-$ enthalpic contribution factor, $\chi_{\mathrm{S}}-$ entropic contribution factor, $V$-molar volume $\left[\mathrm{m}^{3} \mathrm{~mol}^{-1}\right]$, $R$ - gas constant $\left[\mathrm{J} \mathrm{K}^{-1} \mathrm{~mol}^{-1}\right], T$ - room temperature $(298 \mathrm{~K}), \delta_{\mathrm{i}, \mathrm{j}}-$ Hansen solubility parameter for a component $\left[\mathrm{MPa}^{1 / 2}\right]$. Constant term adds contribution resulting from the entropic effects. For non-polar systems, 0.34 is a commonly used value. ${ }^{10,11,12}$ The following $\delta$-parameter literature values for polystyrene $\left(\delta_{\mathrm{PS}}=18.5\right)^{8}$ and poly $(2$-vinylpyridine $)\left(\delta_{\mathrm{P} 2 \mathrm{VP}}=21.2\right)^{13}$ were used.

Table S7. $\chi_{\mathrm{H}}$ parameter calculations for DMOT and TMOT mixtures with toluene.

\begin{tabular}{lccccccc}
\hline $\begin{array}{c}\text { Solvent } \\
\text { mixture }\end{array}$ & TOL & DMOT & TMOT & $\begin{array}{c}\text { DMOT/TOL } \\
\mathbf{1 : 4}\end{array}$ & $\begin{array}{c}\text { DMOT/TOL } \\
\mathbf{1 : 9}\end{array}$ & $\begin{array}{c}\text { TMOT/TOL } \\
\mathbf{1 : 4}\end{array}$ & $\begin{array}{c}\text { TMOT/TOL } \\
\mathbf{1 : 9}\end{array}$ \\
\hline$\chi \mathrm{PS}$ & 0.00 & 0.00 & 0.05 & 0.00 & 0.00 & 0.00 & 0.00 \\
$\chi \mathrm{P} 2 \mathrm{VP}$ & 0.36 & 0.37 & 0.26 & 0.37 & 0.36 & 0.35 & 0.35 \\
& & & & & & & \\
\hline
\end{tabular}




\section{Scherrer analysis}

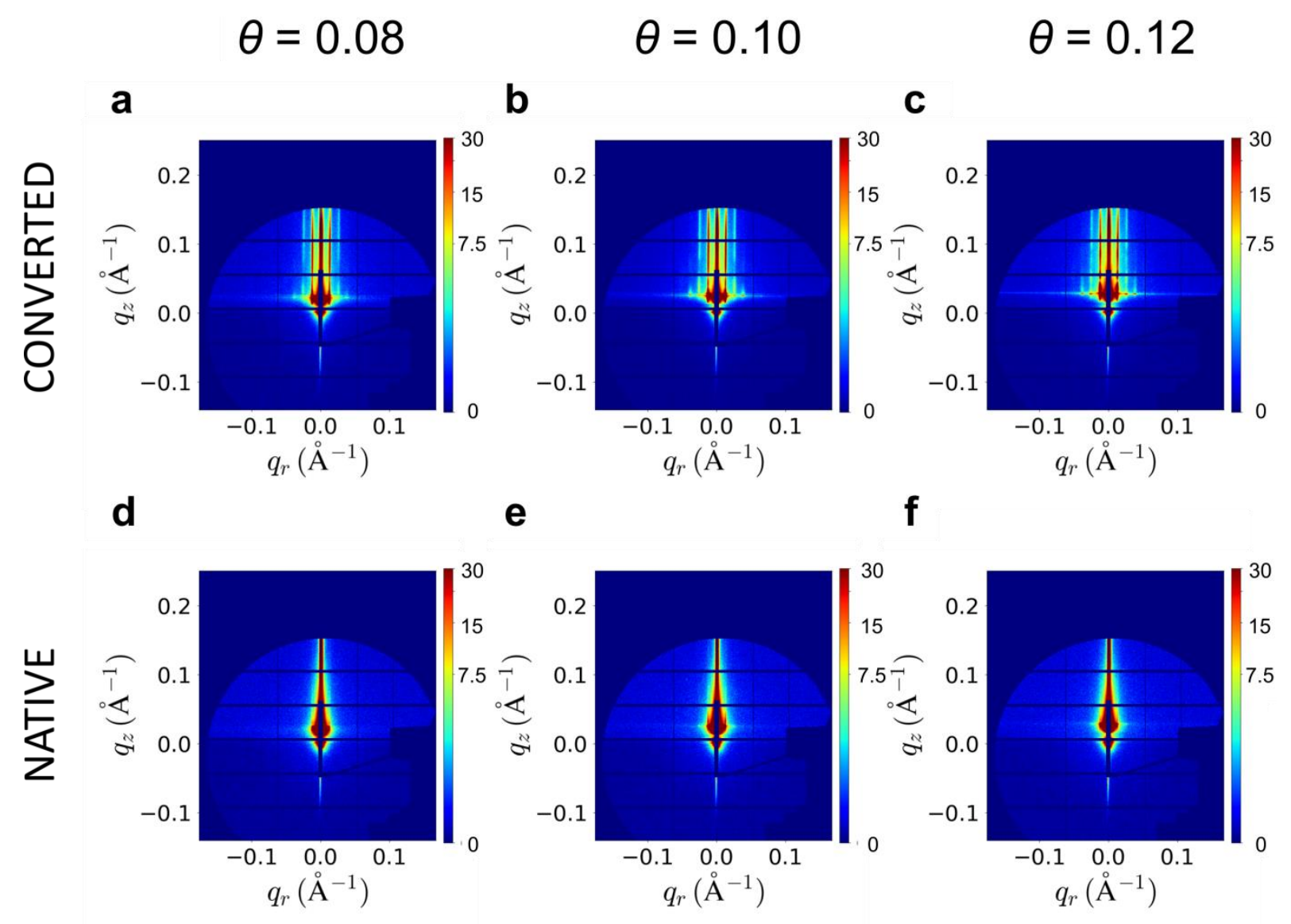

Figure S12. 2D scattering patterns of $\mathrm{Al}_{2} \mathrm{O}_{3}$ converted (a, b, c) and native (d, e, f) S2VP C116 thin films after casting and free evaporation from the DMOT:Tol 1:4 mixture at $25^{\circ} \mathrm{C}$. The patterns are nearly the same for $0.08-0.12^{\circ}$ beam incidence angles. The native samples display much weaker scattering intensity.

a

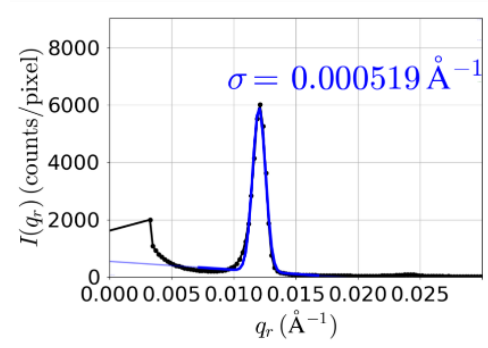

b

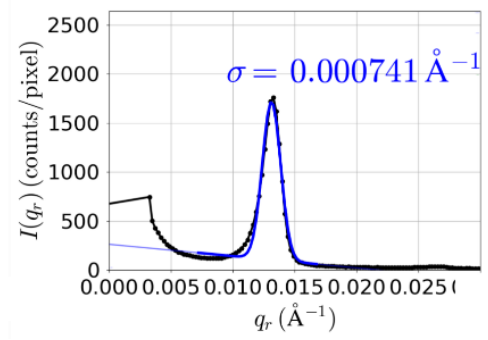

C

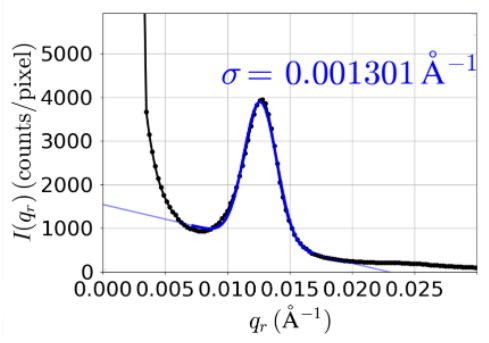

Figure S13. Integrated linecuts of scattering patterns of C116 samples after evaporation of samples at $45^{\circ} \mathrm{C}$ : under the evaporating cap with a) $7 \mathrm{~mm}$ orifice, b) free evaporation, and c) evaporation with 8 L/min gas-flow. The profiles were fitted to the Gaussian function (blue curves) with the standard deviation, $\sigma$, subsequently used in the Scherrer grain-size calculation. 
The GISAXS grain size $\xi$ was evaluated using the Scherrer equation:

$$
\xi=\frac{K \lambda}{\Delta(2 \Theta) \cos \Theta}
$$

where $K$ is a dimensionless shape factor, $\lambda$ is the X-ray wavelength [nm], $\Delta$ is a peak full-width at halfmaximum parameter $-F W H M[\mathrm{rad}]$, and $\Theta$ is the Bragg diffraction angle [rad]. Using the momentum transfer vector formula to convert between the real- and reciprocal-space peak widths:

$$
\begin{aligned}
& q=\frac{4 \pi}{\lambda} \sin 2 \Theta / 2 \\
& \sin 2 \Theta / 2=q \frac{\lambda}{4 \pi}
\end{aligned}
$$

Assuming $\sin (2 \Theta / 2) \approx 2 \Theta / 2$, valid for small scattering angles:

$$
\Delta(2 \Theta)[\mathrm{rad}]=\frac{2 \cdot F W H M\left[\AA^{-1}\right] \cdot \lambda[\AA ̊]}{4 \pi}
$$

therefore:

$$
\xi[\AA]=\frac{2 \pi K}{F W H M\left[\AA^{-1}\right] \cos \Theta}
$$

For $K \approx 1$ and $\cos \Theta \approx 1$, the equation can be simplified to:

$$
\xi[\AA]=\frac{2 \pi}{F W H M\left[\AA^{-1}\right]}
$$

The instrumental broadening was estimated from the scattering pattern of a high-resolution sample (diffraction grating with $80 \mathrm{~nm}$ pitch). It was estimated to be $0.0002 \AA^{-1}(F W H M)$ and accounted for in grain-size calculations:

$$
F W H M=\sqrt{\left(F W H M_{M E A S U R E D}\right)^{2}-\left(F W H M_{\text {INSTRUMENTAL }}\right)^{2}}
$$

The SAXS patterns analysis was performed using the SciAnalysis package. ${ }^{14}$ The $q_{\mathrm{y}}$ profiles of the primary scattering peak at $q^{*}=0.0125 \AA^{-1}$ were fitted to the Gaussian function. The peak $F W H M$ parameters were calculated from the Gaussian $\sigma$, using a formula: $F W H M=2.355 \times \sigma$. We note that in the scattering configuration used in this study $(\lambda=0.9184 \AA$, sample-to-detector distance $=5 \mathrm{~m})$, the resolution of the detector i.e. detector pixel size is $0.00024 \AA^{-1}$ in the reciprocal-space units. Obtaining a reliable Gaussian peak is therefore limited by this resolution and, assuming the $F W H M_{M E A S U R E D}=2 \times$ pixel-size, the maximum resolvable grain size is $\approx 1.5 \mu \mathrm{m}$. 


\section{References}

(1) Stafford, C. M.; Roskov, K. E.; Epps, T. H.; Fasolka, M. J. Generating Thickness Gradients of Thin Polymer Films via Flow Coating. Rev. Sci. Instrum. 2006, 77, 023908.

(2) Leniart, A. A.; Pula, P.; Sitkiewicz, A.; Majewski, P. W. Macroscopic Alignment of Block Copolymers on Silicon Substrates by Laser Annealing. ACS Nano 2020, 14, 4805-4815.

(3) 3,4-dimethoxytoluene http://www.thegoodscentscompany.com/data/rw1183611.html (accessed Jul 28, 2020).

(4) 3,4,5-trimethoxytoluene http://www.thegoodscentscompany.com/data/rw1182721.html (accessed Jul 28, 2020).

(5) Toluene https://www.sigmaaldrich.com/catalog/product/sial/244511 (accessed Jul 28, 2020).

(6) 1,3,5-Trimethylbenzene https://www.sigmaaldrich.com/catalog/product/supelco/442236 (accessed Jul 28, 2020).

(7) Hansen, C. M. Hansen Solubility Parameters: A Users Handbook, Second Edition; CRC Press: Boca Raton, 2007.

(8) Barton, A. M. Handbook of Polymer-Liquid Interaction Parameters and Solubility Parameters; CRC Press: Boca Raton, 2018.

(9) Stefanis, E.; Panayiotou, C. Prediction of Hansen Solubility Parameters with a New GroupContribution Method. Int. J. Thermophys. 2008, 29, 568-585.

(10) Brandrup, J.; Grulke, E. A. Polymer Handbook, 4th ed.; Abe, A., Bloch, D. R., Eds.; A WileyInterscience Publication: New York, 1999.

(11) Emerson, J. A.; Toolan, D. T. W.; Howse, J. R.; Furst, E. M.; Epps, T. H. Determination of Solvent-Polymer and Polymer-Polymer Flory-Huggins Interaction Parameters for Poly(3Hexylthiophene) via Solvent Vapor Swelling. Macromolecules 2013, 46, 6533-6540.

(12) Blanks, R. F.; Prausnitz, J. M. Thermodynamics of Polymer Solubility in Polar and Nonpolar Systems. Ind. Eng. Chem. Fundam. 1964, 3, 1-8.

(13) Arichi, S.; Matsuura, H.; Tanimoto, Y.; Murata, H. Studies of Poly-2-Vinylpyridine. II. Solubilities in Various Solvents. Bull. Chem. Soc. Jpn. 1966, 39, 434-439.

(14) Yager, K. G. SciAnalysis http://gisaxs.com/index.php/SciAnalysis (accessed Aug 15, 2020). 